\title{
STRESS RESPONSE AND INITIAL STIFFNESS OF SIDE PLATE CONNECTIONS TO WCFT COLUMNS
}

\author{
Han-Chao Liu ${ }^{1,2}$, Ji-Ping Hao ${ }^{1, *}$, Qiang Xue ${ }^{1,2}$ and Yu-Qi Huang ${ }^{1,2}$ \\ ${ }^{I}$ School of Civil Engineering, Xi'an University of Architecture \& Technology, Xi'an 710055, China \\ ${ }^{2}$ Design Institute of Xi' an University of Architecture \& Technology, Xi'an 710055, China \\ *(Corresponding author: Email: hao-jp168@163.com)
}

\section{A B S T RA C T}

To study the mechanism of load transfer in double-side-plate connections between I-beams and wall-type concrete-filled steel tubular columns, a pseudo-static experiment and finite element analysis were conducted for two full-scaled specimens. The results revealed that the primary load was transmitted along an S-shaped path in the side plate, and the primary strain occurred in an X-shaped region between the left and right steel beam flanges. The shear force in the steel beam web was transmitted first to the side plate centre and then to the joint area, where the side plate, steel tube web, and concrete all resisted the internal force. Based on principal component methods, a calculation formula was established for initial rotational stiffness that comprehensively considers the influence of the tensions, compression, and shear deformation of the cover plate, side plate, and web. Comparing this formula with an existing model showed that the proposed formula is suitable for new types of side plate joints. Moreover, it can accurately calculate the initial rotational stiffness of the joint, thus providing a reliable basis for future engineering design.

\section{A R T I C LE H I S T O RY}

$\begin{array}{ll}\text { Received: } & 26 \text { November } 2020 \\ \text { Revised: } & 26 \text { April } 2021 \\ \text { Accepted: } & 26 \text { April } 2021\end{array}$

$\begin{array}{ll}\text { Revised: } & 26 \text { April } 2021 \\ \text { Accepted: } & 26 \text { April } 2021\end{array}$

\section{K E Y W O R D S}

Wall-type concrete-filled steel

tubular column;

Double side plate

Load transfer mechanism;

Initial rotational stiffness;

Principal component method

\section{Introduction}

High energy consumption, heavy pollution, and low quality have significantly hindered advancements in the traditional construction industry in China [1]. To address this issue, prefabricated steel structures that offer environmental sustainability, industrialisation, and standardisation have been developed [2]. To meet the general requirements for large-space, low-consumption, and high-quality housing, in this study we combined existing technologies and developed a wall-type concrete-filled steel tubular (WCFT) column building system [1-4].

During the Northridge Earthquake of 1994 in the United States and the Kobe Earthquake of 1995 in Japan, we learned significant lessons about the damage that can occur, particularly to steel structures [5]. To ensure adequate strength, stiffness, and ductility, various connections have been proposed. Among these, the most promising is the side plate method, which offers outstanding behaviour and numerous advantages [6]. Such side plates were first tested by Sabo et al. [7-8]; however, the specimens tested exhibited poor performance owing to their size and configuration. Improved side plate designs were subsequently tested by Houghton and Crawford et al. [6-11], who used a pair of parallel full-depth side plates to connect beams to wide-flange columns. Their results demonstrated a joint rotation capacity that met the 2010 American Institute of Steel Construction requirements. Moreover, the ductility and rotation capacity of the joint were significantly improved by using an optimised weld connection. Faridmehr et al. [12] tested the cyclic characteristics of eight full-scale unstiffened extended end-plates with variable parameters and one side plate moment connection. They found that the performance of the side plate moment connection was superior to that of the end-plates.

Jalai et al. [13-15] proved that steel moment-resisting frames (SMRFs) with side plate connections have good seismic performance, and proposed and calibrated a connection model to represent the side plate connection behaviour. Liu et al. [16] established a new double side-plate I-beam on a WCFT column and investigated its seismic performance. Huang et al. [17] evaluated three full-scale WCFT column joints under cyclic loads and studied the mechanical characteristics of the joint panel zone under shear. They found that the side plate joint exhibits preferable deformation performance and possesses an energy dissipation capacity.

Research methods on connections typically fall into three categories, all of which were utilised in this study: experimental research, numerical simulations, and the component method [18-19]. The component method divides joints into several basic components. Each component is simulated by a one-dimensional spring element, and the overall mechanical behaviour of the joint is calculated by combining the springs in series and in parallel. The quantitative component combination expressions for many common components are listed in the
British standard BS EN 1993-1-8:2005. Furthermore, Weynand [20], Nethercot [21-25] and other researchers studied and extended the component method to varying degrees.

Although the behaviours of side plate connections have been extensively investigated, most of the research has concentrated on I-beam connections to wide flanges or box columns. To the best of our knowledge, no analytical or experimental investigation has been conducted on the transfer mechanism and initial rotational stiffness for I-beam connections to WCFT columns. This is a new type of member section, with small cross-sectional thicknesses and width-to-thickness ratios no greater than 1:4 [3]. Moreover, a new double-side plate (DSP) connection [26-27] is herein proposed based on the characteristics of the section formed on connection with the WCFT column (Fig. 1)

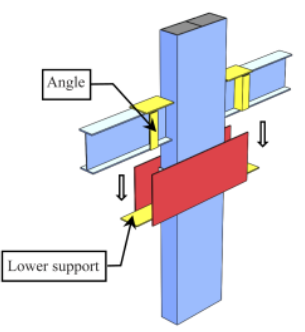

(a) Installation view

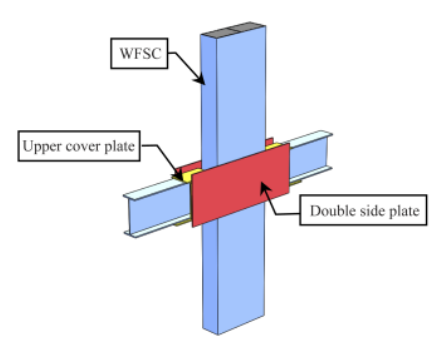

(b) Axonometric view

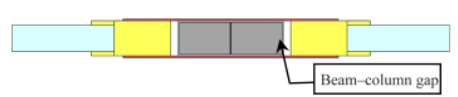

(c) Top view

Fig. 1 Double-side-plate connection overview. (a) Installation illustration, (b) axonometric projection, and (c) top view of the connection 
In this study, we analysed the load transfer mechanism of these joints through both experimental research and numerical simulations. Additionally, the component method was introduced to the side plate joint analysis for the first time. To accomplish this objective, the basic components of the joint force transmission were identified and clarified, and the calculation formula for initial rotational stiffness of the joint was derived using the principles of component transmission. The research results obtained in this study can be used to improve the design theory of this type of joint and provide a research basis for its application to WCFT column structures.

\section{Transfer mechanism}

In this section, we discuss how the nonlinear finite element analysis software ABAQUS was used to establish a fine finite element model (FEM) of the proposed joint. Additionally, a reasonable material constitutive model is used to analyse the transfer mechanism of the joint.

\subsection{Model parameters}

The beam-column section of the model was obtained from WCFT column and steel beam sections in real-world engineering situations. The column cross-section was $200 \times 600 \mathrm{~mm}^{2}$, the wall thickness was $8 \mathrm{~mm}$, and the height was $2800 \mathrm{~mm}$. The beam cross-sectional size was $\mathrm{H} 350 \times 175 \times 7 \times 11$, and the length was $1600 \mathrm{~mm}$. According to the relevant specifications [28], the steel material properties were tested; the corresponding material properties for each plate are given in Table 1. The compressive strength of the concrete was obtained through standard cube tests, and the average compressive strength of the concrete used to fill the WCFT column was determined to be $32.3 \mathrm{MPa}$ by standard cube tests.

Table 1

Measured mechanical properties of steel

\begin{tabular}{|c|c|c|c|c|c|c|}
\hline Component & $\begin{array}{l}\text { Thickness } \\
(\mathrm{mm})\end{array}$ & $\begin{array}{c}f_{\mathrm{sm}} \\
/ \mathrm{MPa}\end{array}$ & $\begin{array}{c}f_{\mathrm{su}} \\
/ \mathrm{MPa}\end{array}$ & $\begin{array}{c}E_{\mathrm{s}} \\
/ \mathrm{MPa} \\
\end{array}$ & $\begin{array}{c}\delta \\
1 \% \\
\end{array}$ & $\begin{array}{l}f_{\text {su }} \\
/ f_{\text {su }} \\
\end{array}$ \\
\hline Column partition & 4.60 & 318.5 & 475.2 & $2.05 \times 10^{5}$ & 40.1 & 1.49 \\
\hline Column siding & 7.68 & 317.9 & 481.9 & $2.08 \times 10^{5}$ & 40.1 & 1.52 \\
\hline Beam web & 6.72 & 317.2 & 449.2 & $2.09 \times 10^{5}$ & 37.1 & 1.42 \\
\hline Beam flange & 10.23 & 283.2 & 434.6 & $2.03 \times 10^{5}$ & 41.6 & 1.53 \\
\hline Stiffener & 5.56 & 228.1 & 355.0 & & 27.0 & 1.56 \\
\hline Side plate & 9.67 & 315.4 & 454.4 & $2.06 \times 10^{5}$ & 27.5 & 1.54 \\
\hline Angle & 5.72 & 250.8 & 396.0 & - & 27.7 & 1.58 \\
\hline
\end{tabular}

Notes: $f_{\mathrm{sm}}$ is yield strength, $f_{\mathrm{su}}$ is tensile strength, $E_{\mathrm{s}}$ is elastic modulus, $\delta$ is elongation.

\subsection{Refined finite element model}

\subsubsection{Element types and meshing}

The steel tube, steel beam, and side plate each utilised 4-node reduced integral shell element S4R with six degrees of freedom, while the concrete utilised an 8-node reduced integral solid element C3D8R with three translational degrees of freedom. Notably, S4R and C3D8R have good adaptability for most nonlinear analyses [29]. Optimal mesh density was determined by mesh convergence analysis to reduce calculation time and ensure sufficient accuracy.

A considerable difference exists between the proposed double side-plate joint and conventional beam-column joint structures in terms of the multiple plate overlaps. Simplifying the overlapping of plates with the column and the beam as a single thicker plate will enlarge the plate contribution. If each of these plates is represented by two separate plates, the DOFs of the two plates must be coupled at the boundary position, and the corresponding nodes must be restrained separately. If they are not properly set, additional constraint stiffness will be introduced, causing the calculation results to deviate from the actual stress situation. After many trial calculations and verifications, each overlapping plate was modelled according to its actual location in space, and a weld element was set at the boundary between them. Thus, the overlapping plates only connected with each other through the weld at the boundary position, while the stresses within were relatively independent and connected.

\subsubsection{Contact analysis model}

The concrete is divided into two parts by a steel plate partition, each of which establishes a contact relationship with either the steel tube or partition steel plate. The contact is limited by the slip surface-to-surface contact, and the normal direction of the contact interface is hard contact. Arbitrary contact pressure can be transmitted through the master-slave contact, and when the contact pressure is zero, the two sides are separated. In the contact model, the tangential behaviour adopts an improved isotropic Coulomb friction model, and the tangential friction coefficient is 0.6 [3].

\subsubsection{Boundary}

In the FEM, constraints are placed on the three translational displacements of the bottom reference point, the rotational displacements along the vertical axis, and the out-of-plane displacements of the column top reference point. Thus, the out-of-plane and vertical displacement of the beam end are restrained (Fig. 2).

\subsubsection{Material constitutive model}

To accurately simulate the mechanical properties, a mixed hardening constitutive model [30] is adopted for steel portions and welds under cyclic loads, which includes both nonlinear follow-up and isotropic strengthening portions. The concrete in the WCFT columns is restrained by the steel tubes, which becomes clear with increasing steel yield strength and decreasing width-to-thickness ratios for the steel plates. The stress-strain relationship of the confined concrete is based on its damage plasticity model in accordance with the Binici model [31]. The resulting FEM and weld elements for the DSP used in this study, denoted as DSP1, are shown in Figs. 2(a) and (b), respectively.

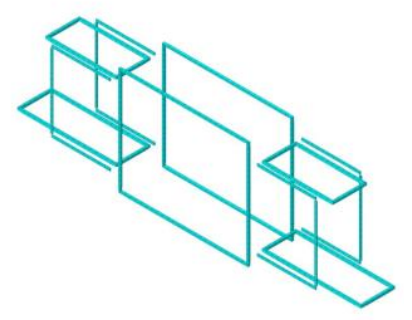

(b) Weld elements of DSP1 


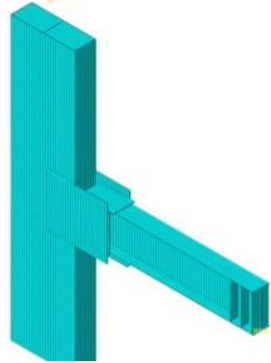

(c) Model of DSP2

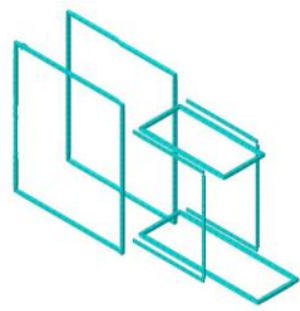

(d) Weld elements of DSP2

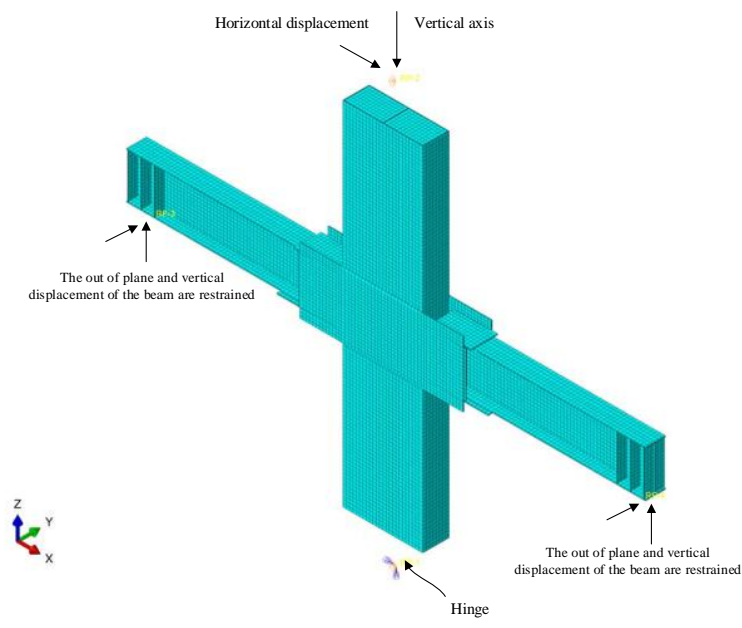

(e) Boundary

Fig. 2 Finite element models for (a-b) DSP1 and (c-d) DSP2, including (a-c) the overall model of each specimen as well as (b-d) weld elements.

\subsection{Transfer mechanism analysis}

The principal stress distribution for the peak joint forward load is shown in Fig. 3. The principal tensile stress (Fig. 3(a)), in the horizontal direction of the upper flange of the left steel beam is transmitted first to the side plate through the weld, and then to the joint through the side plate. Some of the principal tensile stress is transmitted to the wall column web through the weld, and some

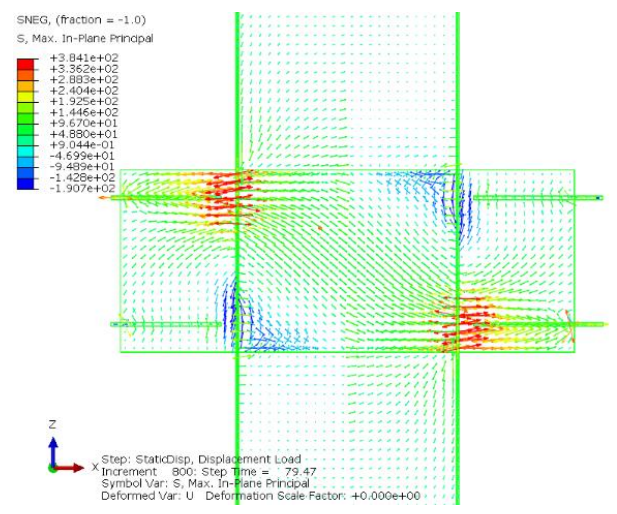

(a) is passed directly downward to the lower flange of the right steel beam. The principal compressive stress (Fig. 3(b)) follows a similar transmission path, from the lower flange of the left steel beam to the upper flange of the right steel beam through the side plate and joint regions. The web shears of the steel beam are transmitted to the middle of the side plate first, and then to the joint region. The side plate, steel tube web, and concrete all resist the internal force in the joint region.

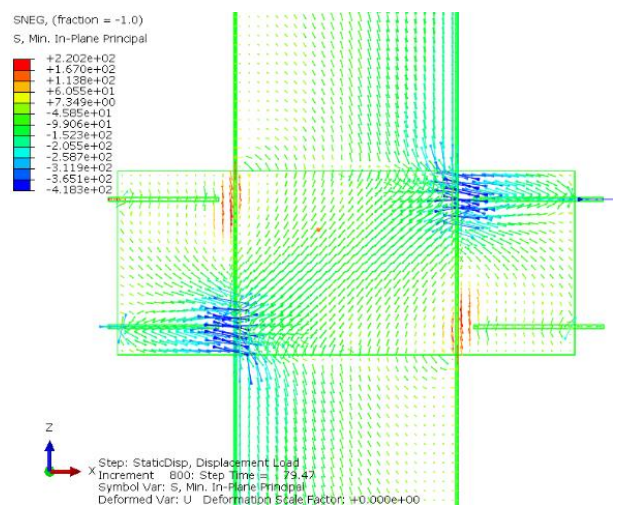

(b)

Fig. 3 DSP1 Transmission path. Principal (a) tensile and (b) compressive load transfers

The side plate stress distribution corresponding to the peak load is shown in Fig. 4. The shear force and moment at the end of the beam-column is approximately transformed into the coupled forces acting on the geometric centre of the upper and lower flanges and the shear force acting on the web. In Fig. 4(a), we observe that the side plate bears the majority of the force transmitted from the steel beam flange in the horizontal direction, exhibiting tension and pressure bands. The stress gradually transmits from the flange to the side plate along the connection weld, and then through this weld to the WCFT column, while the side plate stress gradually decreases. As shown in Fig. 4(b), the side plate also bears the majority of the vertical force transmitted by the wall column flange through the vertical weld. This stress is the largest at the corner connecting the side plate with the column flange. Notably, the compressive stress is greater than the tensile stress under axial pressure. With an increasing distance from the vertical weld, the vertical stress on the side plate decreases rapidly.

Figs. 4(c) and (d) present the principal stress distribution of the side plate, indicating that the principal tensile stress is primarily transmitted in an oblique manner from the upper flange of the left steel beam to the lower flange of the right steel beam through the joint region. The principal compressive stress is primarily transmitted obliquely from the lower flange of the left steel beam to the upper flange of the right steel beam through the joint region. Additionally, the steel beam web shear force is transmitted to the side plate through the connecting angle steel, creating a diagonal principal stress zone in the connection between the steel beam and side plate that is roughly perpendicular to the principal stress direction of the joint region. Therefore, the overall principal load transfer path in the side plate is approximately S-shaped. The 
shear stress distribution and the von Mises equivalent stress in the side plate are shown in Figs. 4(e) and (f), respectively. The shear stress is largest in the joint; however, it is still smaller than the shear yield of the steel. Fig. 4(f) demonstrates that the side plate in the column range is effectively elastic. The side plate at the beam-column gap transfers all forces to the beam end, resulting in maximal stress. The side plate in the corresponding position on the steel beam flange exceeds the yield stress and thus enters a yield state. Further, the side plate in the corresponding position on the steel beam web transmits the shear force and has a low stress level, thus forming the 'elastic core'. Fig. 4(g) shows the principal strain distribution of the side plate. Notably, the principal tensile and compressive strains are consistent with the stress distribution, forming an X-shaped distribution between the left and right steel beam flanges. Fig. 4(h) shows the cumulative plastic strain distribution on the side plate produced at the beam-column gap. Owing to the stress concentration, the cumulative plastic strain of the weld joint corner between the side plate and column is large. Thus, special attention should be given to this condition so that damage to the corner weld can be avoided in this design.

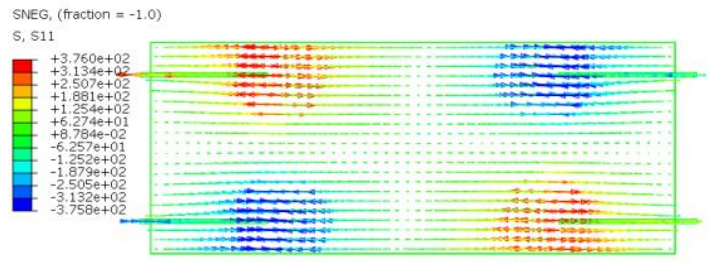

(a)

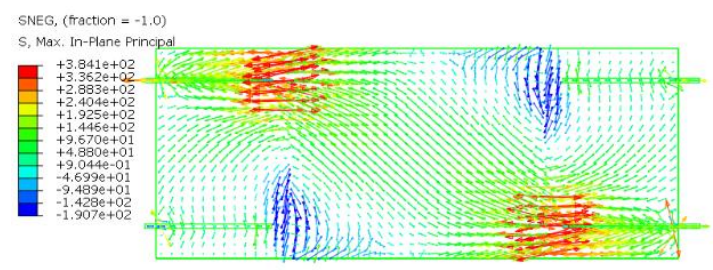

(c)

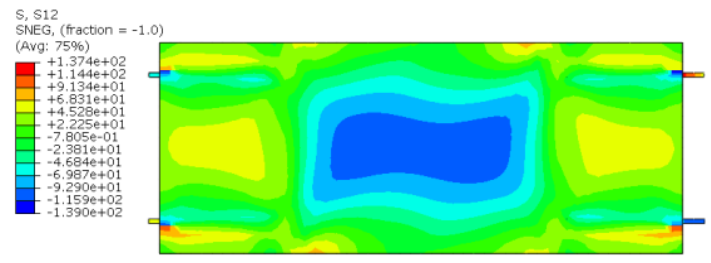

(e)

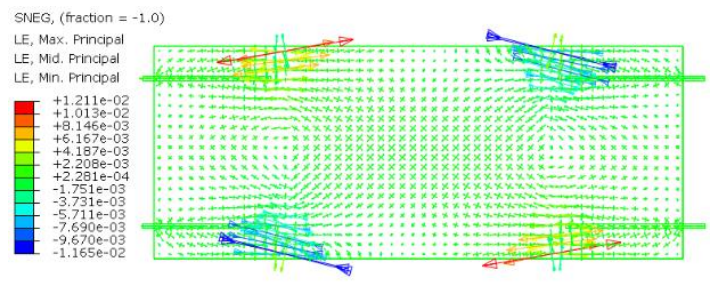

(g)

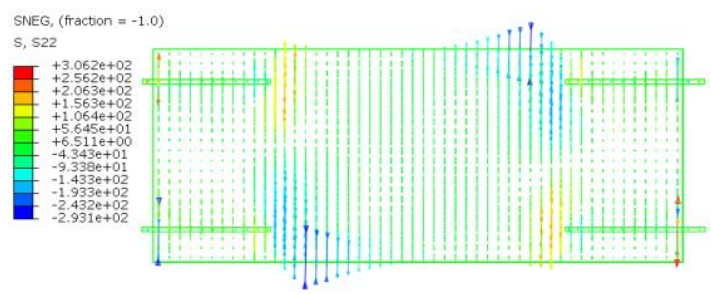

(b)

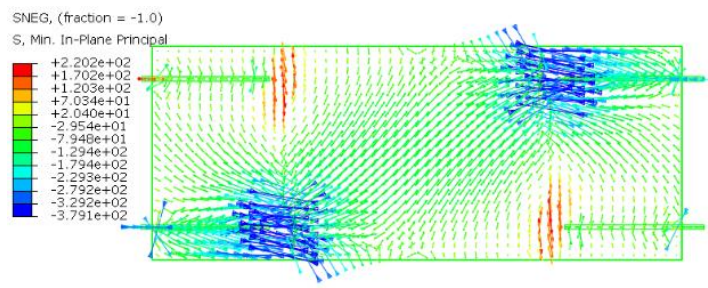

(d)

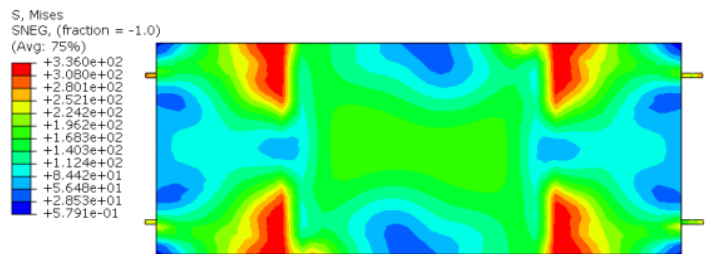

(f)

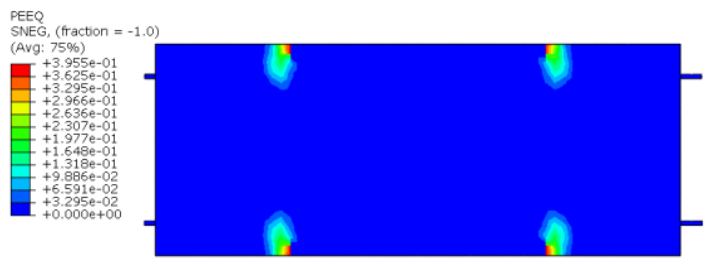

(h)

Fig. 4 Stress distribution on the side plate in DSP1. (a) Horizontal stress, (b) vertical stress, (c) principal tensile stress, (d) principal compressive stress, (e) shear stress, (f) von Mises stress equivalent, (g) principal strain, (h) cumulative plastic strain

(a)

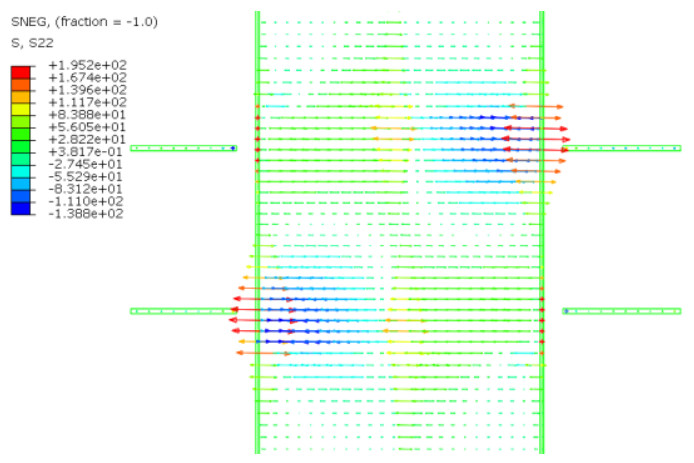

(b)

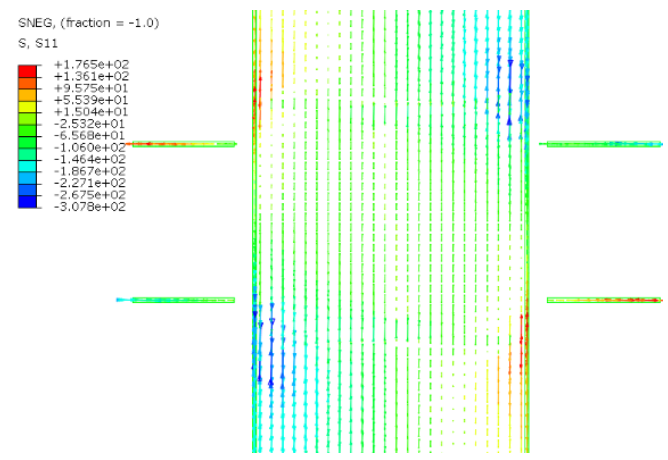


(c)

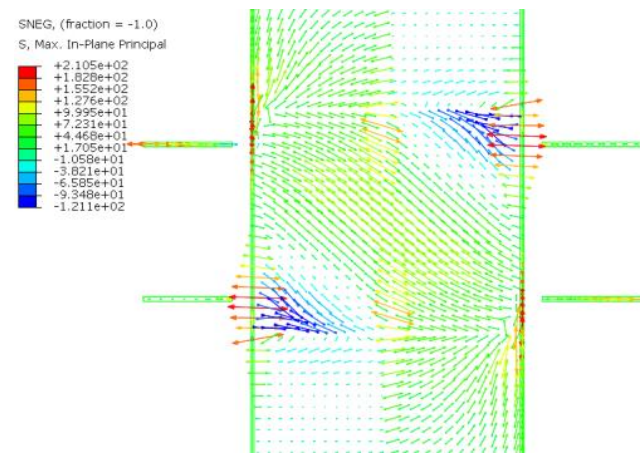

(e)

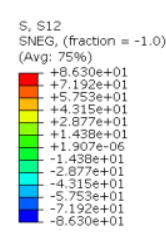

(g)

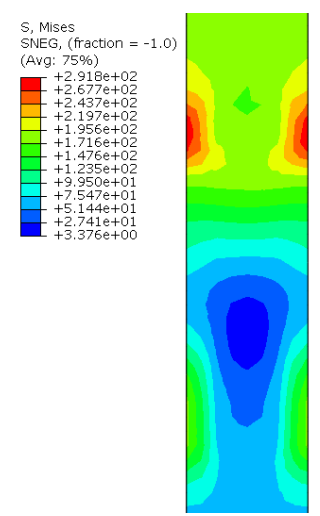

(d)

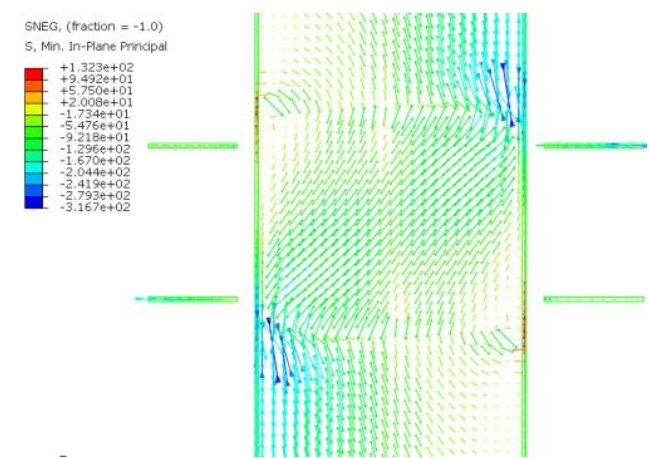

(f)

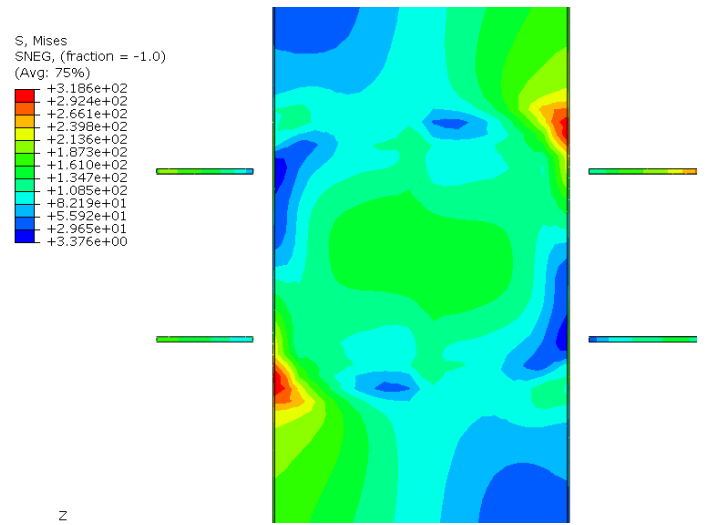

(h)

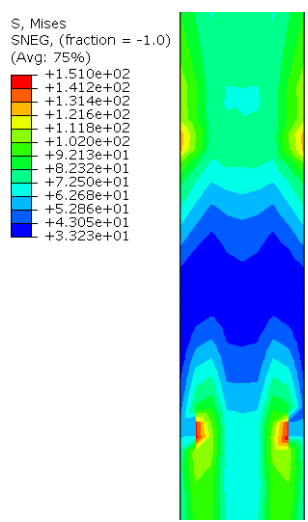

Fig. 5 Stress distribution of steel tube in DSP1. (a-f) Steel tube web (a) horizontal stress, (b) vertical stress, (c) principal tensile stress, (d) principal compressive stress, (e) shear stress, (f) von Mises stress; $(\mathrm{g}-\mathrm{h})$ von Mises stress of the steel tube $(\mathrm{g})$ flange and $(\mathrm{h})$ diaphragm

Fig. 5 shows the steel tube stress distribution corresponding to the peak load. As shown in Fig. 5(a), the horizontal stress is concentrated at the position corresponding to the compression flange of the steel beam. Here, the steel tube web primarily bears the compressive stress transmitted from the side plate through the weld, causing deformation relative to the internal concrete. Because the corner of the steel tube is restrained by the concrete, this deformation trend is prevented, and high tensile stress is generated. The adjacent position exhibits compressive stress with a large stress gradient. Contrarily, the horizontal stress at the position corresponding to the steel beam tension flange is relatively uniform. The steel tube is separated from the concrete under the tensile stress, thus this stress is uniformly transmitted to the steel tube web.

Fig. 5(b) reveals that the vertical stress in the steel tube is transmitted to the side plate through the weld. Consequently, the stress level in the joint region is significantly lower than in the adjacent position. The principal tensile and compressive stress distribution diagrams of the steel tube web are shown in Figs. 5(c) and (d), respectively. Near the joint, the steel tube web exhibits oblique principal tensile stress and principal compressive stress bands under the column and beam action. Because there is still axial pressure in the column, the principal compressive stress is greater than the principal tensile stress. At the position corresponding to the steel beam compression flange, the steel tube is restrained by concrete, and the stress is relatively concentrated. The steel tube diaphragm position is also affected by this condition, and the local stress is high. Fig. 5(e) provides the shear stress of the steel tube web, and Figs. 5 (f)-(h) show the von Mises equivalent stresses of the steel tube web, flange, and diaphragm, respectively. The shear stress is primarily observed near the joint and is in an elastic state. A large stress is exhibited in the corner of the welding position between the steel tube web and side plate, and the adjacent steel enters a yield state. The equivalent stress of the steel tube flange and diaphragm are effectively elastic.

Fig. 6 shows the stress distribution of concrete in the joint region. There is slippage on the contact interface of the steel tube and concrete, and the stress of the concrete in the two chambers is relatively independent and neither can achieve the combined stress performance. From Figs. 6(a) and (b), it is clear that the concrete bears the majority of the horizontal compressive stress from the steel beam flange and the bending vertical stress of the column. Figs. 6(c) and (d) show the principal tensile and compressive stress of the concrete core, respectively. The tensile stress near the joint reaches the tensile cracking stress, and the local compressive stress at the position corresponding to the steel beam compression flange reaches the concrete compressive strength, but the range is small. Notably, the principal stress for concrete near the joint is smaller than that in the adjacent position. The damage to concrete near the joint is shown in Figs. 6(e) and (f), and the concrete exhibits cracking and compression damage in a small area of stress concentration. Figs. $6(\mathrm{~g})$ and $(\mathrm{h})$ show the contact friction and pressure distribution, respectively, for the concrete surface near the joint. Clearly, the steel tube at the position corresponding to the steel beam compression flange transmits a large pressure to the concrete. Furthermore, the diaphragm of the steel tube forms an effective restriction for the concrete, and the contact pressure is large. 
(a)

(d)

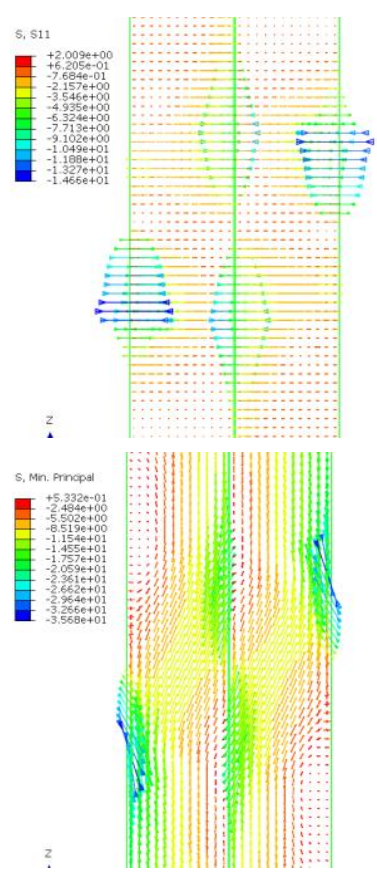

(g)
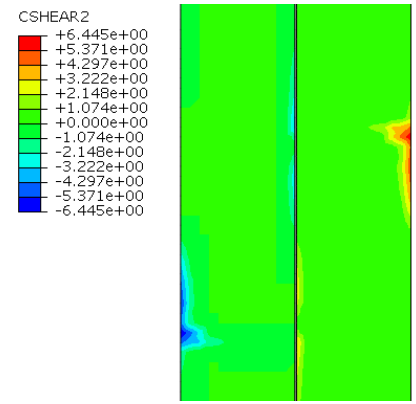

(b)

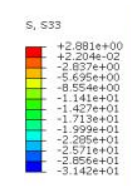

(e)

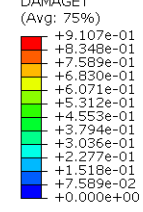

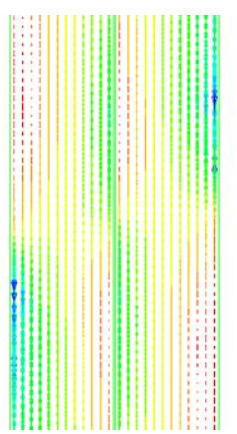

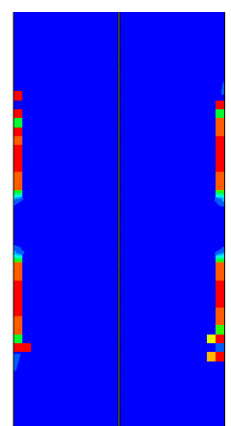

(h) (c)

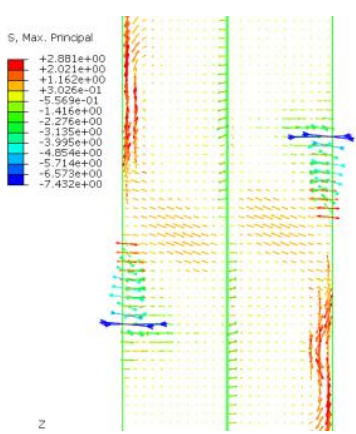

(f)
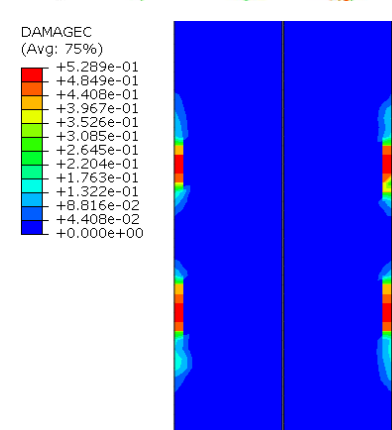

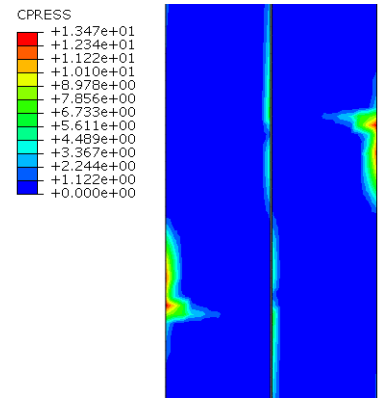

Fig. 6 Stress distribution of concrete in DSP1. (a) Horizontal stress, (b) vertical stress, (c) principal tensile stress, (d) principal compressive stress, (e) tensile damage, (f) compressive damage, $(\mathrm{g})$ surface friction, and $(\mathrm{h})$ surface pressure

\section{Initial rotational stiffness analysis}

Rotational stiffness is a key parameter in describing moment-rotation curves. Generally, joint rotation can be divided into rotations caused by bending and shear deformations [32]. The primary tension components of the joint include the tension in the steel beam flange and cover plate near the side plate, the tension in the side plate, and the tension in the column web. The primary compression components include compression of the steel beam flange and cover plate near the side plate, compression of the side plate itself, and compression in the column web. The main shear components include side plate shear, column web shear, and concrete shear.

In this study, a simplified connection model (Fig. 7) was developed. The joint rotation caused by bending deformation is simplified as the spring model shown in Fig. 7, and the joint bending is converted into a coupled pair of tension and pressure. According to the principles of the component method [25], individual tension and pressure components can be simplified as a single spring element along the centroid direction.

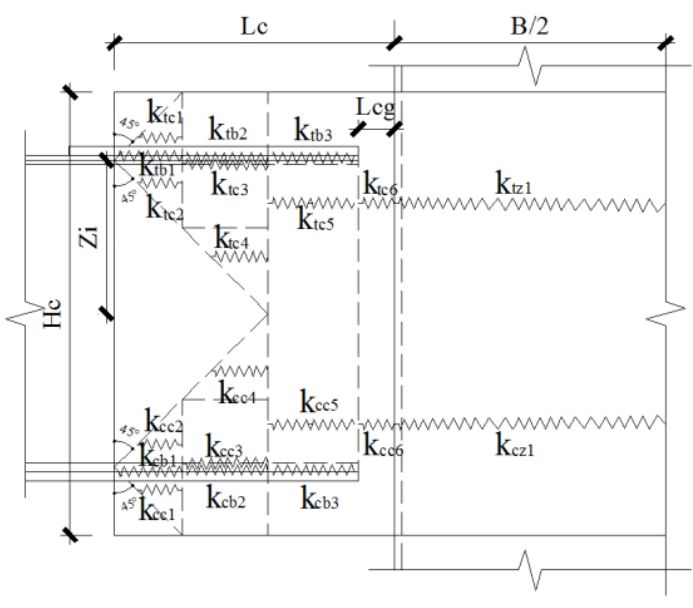

(a)

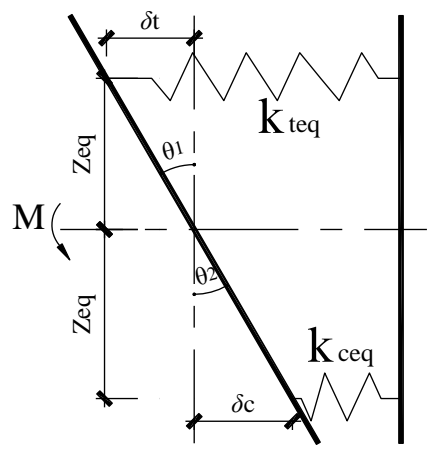

(b)

Fig. 7 Simplified spring model. (a) Tension and compression spring elements, and (b) equivalent spring elements. $\mathrm{k}_{\mathrm{tci}}$, $\mathrm{k}_{\mathrm{tbi}}$, and $\mathrm{k}_{\mathrm{tzi}}$ are the tensile stiffnesses of the side plate, steel

beam/cover plate, and side plate/column web, respectively; $\mathrm{k}_{\mathrm{cci}}, \mathrm{k}_{\mathrm{cbi}}$, and $\mathrm{k}_{\mathrm{czi}}$ are the compression stiffnesses of the side plate, steel beam/cover plate, and side plate/column web, respectively; $\mathrm{k}_{\mathrm{teq}}$ and $\mathrm{k}_{\mathrm{ceq}}$ are the equivalent tension and compression stiffnesses, respectively of the spring element; $Z_{\mathrm{i}}$ is the distance between the centroid of each spring element and the beam centre, and $Z_{\mathrm{eq}}$ is the equivalent distance between the centroid of each spring element and the beam centre 
Corresponding to Fig. 7(b), the following equations are established according to the respective resultant force equivalence and bending distance equivalence:

$$
\begin{aligned}
& k_{t e q} Z_{t e q} \theta_{1}=\sum_{\mathrm{i}=1}^{6} k_{t c i} Z_{t c i} \theta_{1}+\sum_{\mathrm{i}=1}^{3} k_{t b i} Z_{t b i} \theta_{1}+k_{t z 1} Z_{t z 1} \theta_{1} \\
& k_{t e q} Z_{t e q}^{2} \theta_{1}=\sum_{\mathrm{i}=1}^{6} k_{t c i} Z_{t c i}^{2} \theta_{1}+\sum_{\mathrm{i}=1}^{3} k_{t b i} Z_{t b i}^{2} \theta_{1}+k_{t z 1} Z_{t z 1}^{2} \theta_{1} \\
& k_{c e q} Z_{c e q} \theta_{2}=\sum_{\mathrm{i}=1}^{6} k_{c c i} Z_{c c i} \theta_{2}+\sum_{\mathrm{i}=1}^{3} k_{c b i} Z_{c b i} \theta_{2}+k_{c z 1} \mathrm{Z}_{c z 1} \theta_{2} \\
& k_{c e q} Z_{c e q}^{2} \theta_{2}=\sum_{\mathrm{i}=1}^{6} k_{c c i} Z_{c c i}^{2} \theta_{2}+\sum_{\mathrm{i}=1}^{3} k_{c b i} Z_{c b i}^{2} \theta_{2}+k_{c z 1} Z_{c z 1}^{2} \theta_{2}
\end{aligned}
$$

Combining Eqs. (1 to 4 ) yields:

$$
\begin{aligned}
Z_{t e q}= & \frac{\sum_{i=1}^{6} k_{t c i} Z_{t c i}^{2}+\sum_{i=1}^{3} k_{t b i} Z_{t b i}^{2}+k_{t z 1} Z_{t z 1}^{2}}{\sum_{i=1}^{6} k_{t c i} Z_{t c i}+\sum_{i=1}^{3} k_{t b i} Z_{t b i}+k_{t z 1} Z_{t z 1}} \\
Z_{c e q}= & \frac{\sum_{i=1}^{6} k_{c c i} Z_{c c i}^{2}+\sum_{i=1}^{3} k_{c b i} Z_{c b i}^{2}+k_{c z 1} Z_{c z 1}^{2}}{\sum_{i=1}^{3} k_{c c i} Z_{c c i}+\sum_{i=1}^{3} k_{c b i} Z_{c b i}+k_{c z 1} Z_{c z 1}}
\end{aligned}
$$

$$
k_{t e q}=\frac{\left(\sum_{i=1}^{6} k_{t c i} Z_{t c i}+\sum_{i=1}^{3} k_{t b i} Z_{t b i}+k_{t z 1} Z_{t z 1}\right)^{2}}{\sum_{i=1}^{6} k_{t c i} Z_{t c i}^{2}+\sum_{i=1}^{3} k_{t b i} Z_{t b i}^{2}+k_{t z 1} Z_{t z 1}^{2}}
$$

$$
k_{c e q}=\frac{\left(\sum_{i=1}^{6} k_{c c i} Z_{c c i}+\sum_{i=1}^{3} k_{c b i} Z_{c b i}+k_{c z 1} Z_{c z 1}\right)^{2}}{\sum_{i=1}^{6} k_{c c i} Z_{c c i}^{2}+\sum_{i=1}^{3} k_{c b i} Z_{c b i}^{2}+k_{c z 1} Z_{c z 1}^{2}}
$$

The characteristics of new joints produce a very large in-plane stiffness for concrete, compared with the other components, hence the rotation caused by moment deformation in concrete is ignored. Under a pure bending moment, the areas of the joint under tension and compression are symmetrical, and they constitute the tensile and compressive rigidity of the plate. The tensile and compression calculation models and stiffnesses are identical; thus, $Z_{\text {teq }}=Z_{c e q}$, $k_{\text {teq }}=k_{\text {ceq }}$. The mechanical model of the tension plate is shown in Fig. 8 .

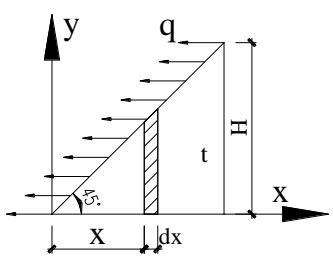

(a) Tension of triangular plate

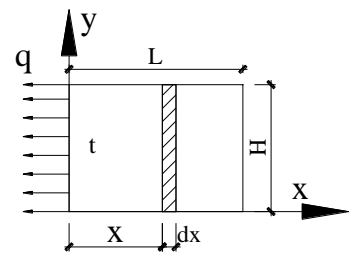

(b) Tension of rectangular plate
Fig. 8 Mechanical model of plate. Illustrations of the tension of (a) triangular and (b) rectangular plates.
According to material mechanics principles, the calculation formula for the tensile stiffness of a plate is Eq. (9). The tension stiffness of the triangular plate (Fig. 8(a)) is calculated according to Eqs. (10 to 14),

$k=\frac{F}{\Delta L}$

$d A=x t$

$d F=d A \times q=x t q$

$\Delta d x=\frac{d F \times d x}{E d A}=\frac{q}{E} d x$

$\Delta L=\int_{0}^{H} \frac{q}{E} d x=\frac{q H}{E}$

$k_{t, t r i}=\frac{F}{\Delta L}=E t$

Similarly, the tensile stiffness of the rectangular plate (Fig. 8(b)) is calculated as:

$k_{t, \text { rec }}=\frac{E H \mathrm{t}}{L}$

Based on Fig. 7 and Eqs. (14 and 15), the spring element parameters can be defined as follows:

$k_{t c 1}=2 E t_{c 1}, \quad k_{t c 2}=2 E t_{c 2}, \quad k_{t c 4}=2 E t_{c 4} \quad k_{t c 3}=\frac{4 E t_{c 3}\left[H_{c}-\left(H_{b}-t_{f}\right)\right]}{2\left(H_{b}-t_{f}\right)-H_{c}}$

$k_{t c 5}=\frac{2 E t_{c 5} H_{c}}{2 L_{c}-\left(H_{b}-t_{f}\right)-2 L_{\mathrm{cg}}}$

$k_{t c 6}=\frac{E t_{c 6} H_{c}}{L_{c g}}, \quad k_{t b 1}=\frac{2 E\left(t_{f} B_{f}+t_{g} B_{g}\right)}{H_{c}-\left(H_{b}-t_{f}\right)}$

$k_{t b 2}=\frac{2 E\left(t_{f} B_{f}+t_{g} B_{g}\right)}{2\left(H_{b}-t_{f}\right)-H_{c}}, \quad k_{t z 1}=\frac{4 E H_{c}\left(t_{c}+t_{z}\right)}{B}$

$k_{t b 3}=\frac{4 E\left(t_{f} B_{f}+t_{g} B_{g}\right)}{2 L_{c}-\left(H_{b}-t_{f}\right)-2 L_{c g}}$

$Z_{t c 1}=\frac{H_{c}+2\left(H_{b}-t_{f}\right)}{6}, \quad Z_{t c 2}=\frac{4\left(H_{b}-t_{f}\right)-H_{c}}{6}$

$Z_{t c 3}=\frac{H_{b}-t_{f}}{2}, \quad Z_{t c 4}=\frac{2\left(H_{b}-t_{f}\right)-H_{c}}{3} Z_{t c 5}=Z_{t c 6}=Z_{t z 1}=\frac{H_{c}}{4}$

$Z_{t b 1}=Z_{t b 2}=Z_{t b 3}=\frac{H_{b}-t_{f}+t_{g}}{2}$

where $H_{b}$ is steel beam height, $t_{f}$ is the beam flange thickness, $t_{g}$ is the cover plate thickness $B_{g}$ is the cover plate width, and $B_{f}$ is the beam flange width. $Z_{\text {teq }}$ 
and $k_{\text {teq }}$ can be obtained by substituting these spring parameters into Eqs. ( 5 to 8).

Referring to [27], the shear stiffness can be calculated as:

$$
k_{v}=\frac{E A_{v c}}{2(1+v) \beta Z_{v}}
$$

where $A_{v c}$ is the shear area, $Z_{v}$ is the shear section height, and $\beta$ is the coefficient related to the connected shear variable. For a side column, one side is sheared, and $\beta=1$. For a middle column, if the bending moment at the beam end is equal and the direction is opposite, $\beta=0$, but if the direction is equal, $\beta$ $=2$.

The shear components of the side plate joints include side plate shear, column side plate/web shear, and concrete shear. The characteristics of new joints produce very large in-plane shear stiffness for concrete compared with the other components. Hence, the rotation caused by shear deformation in concrete is ignored. The parameters of each shear component are as follows

$$
\begin{aligned}
& k_{v, \text { sideplate }}=\frac{E\left(L_{c}-L_{c g}\right) 2 t_{c}}{2(1+v)\left(H_{b}-2 t_{f}\right)} \\
& k_{v, w e b}=\frac{2 E\left(B_{\mathrm{zc}} t_{c}+B t_{z}\right)}{2(1+v) \beta\left(H_{b}-2 t_{f}\right)}
\end{aligned}
$$

(a)

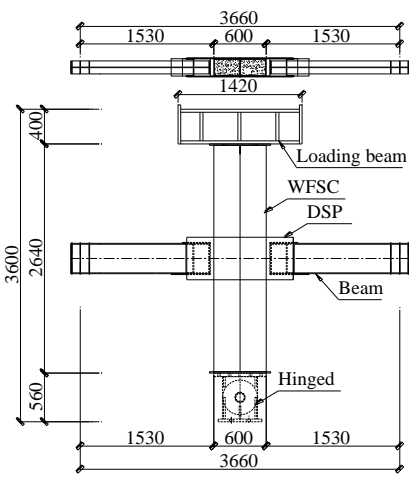

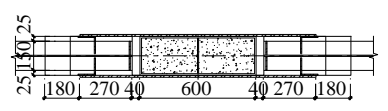

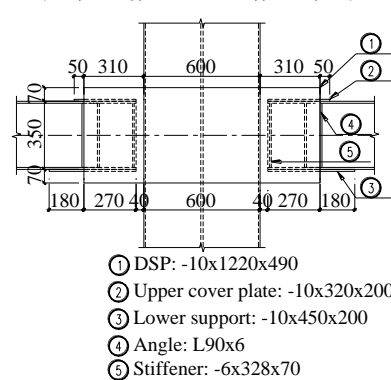

(b)

$\theta_{V}=M\left(\frac{1}{k_{v, \text { sideplate }}\left(H_{b}-2 t_{f}\right)^{2}}+\frac{1}{k_{v, \text { web }}\left(H_{b}-2 t_{f}\right)^{2}}\right)$

Then, the overall initial rotational stiffness for the proposed new joint is:

$S=\frac{M}{\theta}=\frac{1}{\frac{1}{k_{t e q}\left(z_{t e q}+Z_{c e q}\right)^{2}}+\frac{1}{k_{c e q}\left(z_{c e q}+Z_{c e q}\right)^{2}}+\frac{1}{k_{v, s p}\left(H_{b}-2 t_{f}\right)^{2}}+\frac{1}{k_{v, w e b}\left(H_{b}-2 t_{f}\right)^{2}}}$

\section{Experiments and FEM Verification}

To verify the validity of the proposed analysis, we conducted pseudo-static experiments for two full-scale DSP specimens (denoted DSP1 and DSP2), which were based on beam and column models from real-world engineering applications. We performed a multi-parameter extended analysis of this FEM; the parameters of the test and FEM are shown in Table 2 and Fig. 9, respectively. The material properties of each component are provided in Section 1.1, and the axial compression load was $1713.33 \mathrm{kN}$.

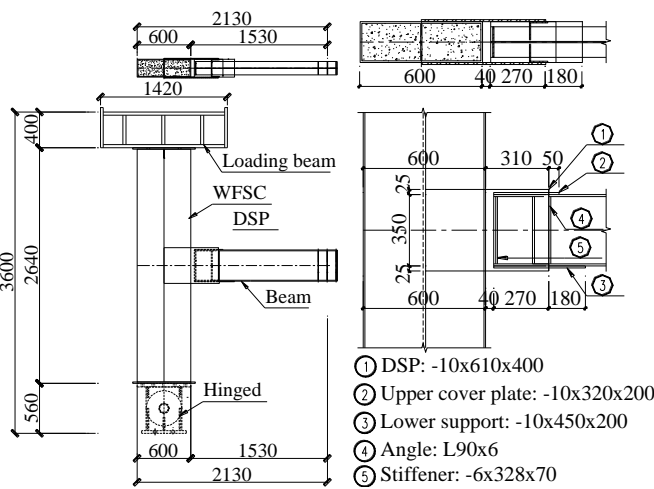

Fig. 9 Specimen details. All dimensions are given in mm. Overall and partial details are provided for (a) DSP1 and (b) DSP2

\begin{tabular}{|c|c|c|c|c|c|c|c|c|c|c|c|}
\hline Model & $\begin{array}{c}\text { Side plate } \\
\text { height } \\
H_{c} / \mathrm{mm}\end{array}$ & $\begin{array}{c}\text { Side plate } \\
\text { thickness } \\
t_{c} / \mathrm{mm}\end{array}$ & $\begin{array}{c}\text { Side plate } \\
\text { extension } \\
\text { length } L_{c} / \mathrm{mm}\end{array}$ & $\begin{array}{c}\text { beam-column } \\
\text { gap length } \\
L_{c g} / \mathrm{mm}\end{array}$ & $\begin{array}{l}\text { Beam } \\
\text { height } \\
H_{b} / \mathrm{mm}\end{array}$ & $\begin{array}{c}\text { Beam } \\
\text { flange } \\
\text { thickness } \\
t_{f} / \mathrm{mm} \\
\end{array}$ & $\begin{array}{c}\text { Cover plate } \\
\text { thickness } \\
t_{g} / \mathrm{mm}\end{array}$ & $\begin{array}{c}\text { Beam } \\
\text { flange } \\
\text { width } \\
B_{f} / \mathrm{mm} \\
\end{array}$ & $\begin{array}{c}\text { Cover plate } \\
\text { width } \\
B_{g} / \mathrm{mm}\end{array}$ & $\begin{array}{l}\text { Column } \\
\text { width } \\
B / \mathrm{mm}\end{array}$ & $\begin{array}{c}\text { Column } \\
\text { web } \\
\text { thickness } \\
t_{z} / \mathrm{mm}\end{array}$ \\
\hline DPS1 & 490 & 10 & 310 & 40 & 350 & 10 & 10 & 150 & 200 & 600 & 8 \\
\hline DPS2 & 400 & 10 & 310 & 40 & 350 & 10 & 10 & 150 & 200 & 600 & 8 \\
\hline DPS1-1 & 520 & 10 & 310 & 40 & 350 & 10 & 10 & 150 & 200 & 600 & 8 \\
\hline DPS1-2 & 460 & 10 & 310 & 40 & 350 & 10 & 10 & 150 & 200 & 600 & 8 \\
\hline DPS1-3 & 430 & 10 & 310 & 40 & 350 & 10 & 10 & 150 & 200 & 600 & 8 \\
\hline DPS2-1 & 490 & 6 & 310 & 40 & 350 & 10 & 10 & 150 & 200 & 600 & 8 \\
\hline DPS2-2 & 490 & 8 & 310 & 40 & 350 & 10 & 10 & 150 & 200 & 600 & 8 \\
\hline DPS2-3 & 490 & 10 & 310 & 40 & 350 & 10 & 10 & 150 & 200 & 600 & 8 \\
\hline DPS2-4 & 490 & 12 & 310 & 40 & 350 & 10 & 10 & 150 & 200 & 600 & 8 \\
\hline DPS2-5 & 490 & 14 & 310 & 40 & 350 & 10 & 10 & 150 & 200 & 600 & 8 \\
\hline DPS2-6 & 490 & 16 & 310 & 40 & 350 & 10 & 10 & 150 & 200 & 600 & 8 \\
\hline
\end{tabular}

Table 2

Parametric definition of the model 


\subsection{Testing system and method}

According to the provisions of JGJ/T101-2015 [33], a pseudo-static experiment can use a column-end loading test device (Fig. 10) to consider the $\mathrm{P}-\Delta$ effect. A force-displacement dual-control loading system is used to transition specimens from the elastic stage to failure. The loading process begins with axial pressure applied, in stages, to the top of the specimen while the shaft pressure is maintained as constant by a voltage stabilisation system. A reciprocating horizontal load is then applied in stages to the specimen top. The distance between the loading point and column bottom is $3000 \mathrm{~mm}$.

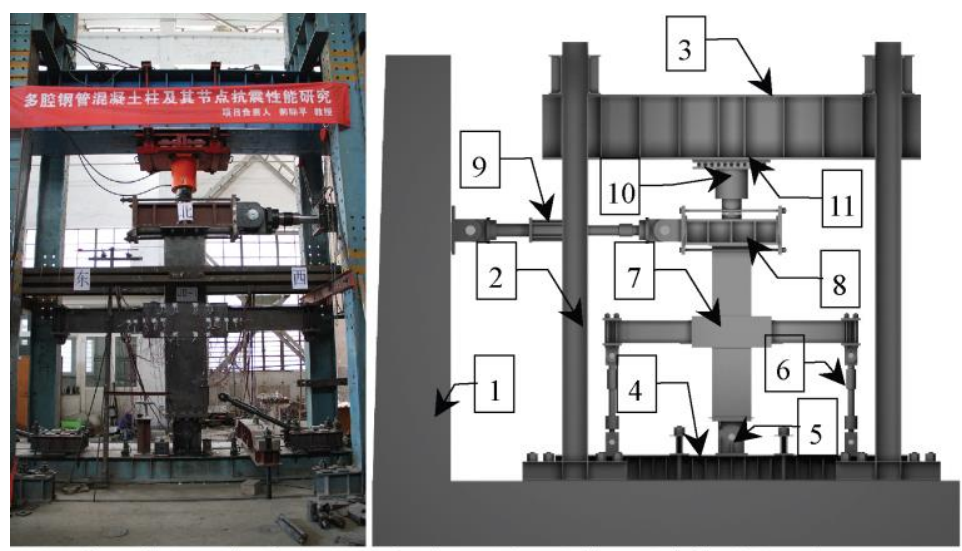

1: Reaction wall; 2 : reaction frame; 3 : reaction beam; 4 : base; 5 : hinge; 6 : rigid rod; 7 : specimens;

8: loading beam; 9 : servo actuator; 10 : jack; and 11: sliding roller

Fig. 10 Test device

The force applied to the specimen was controlled before yielding. The horizontal loading level was $20 \%$ of the predicted yield load, and each load was repeated once. When the specimen deformation speed increased significantly or when the strain, collected by a displacement meter and strain gauges at multiple points on the beam end or side plate, reached the material yield strain, the specimen was determined to have yielded. The corresponding displacement was identified as the joint yield displacement. After yielding, the specimens were subjected to displacement control and were loaded at 0.5 times the yield displacement. Each displacement was repeated three times. When the horizontal load decreased to $85 \%$ of the peak load, or the axial bearing capacity could not be maintained, the loading was considered complete.

During these tests, we measured the axial force and horizontal load exerted on the top of the column, the displacement and angle of the specimen, and the strain of the beam end and side plate. The local buckling development of the steel tube wall plate, longitudinal weld cracking of the steel tube itself, and concrete crushing were also observed and recorded. The measurement setup is summarised in Fig. 11.

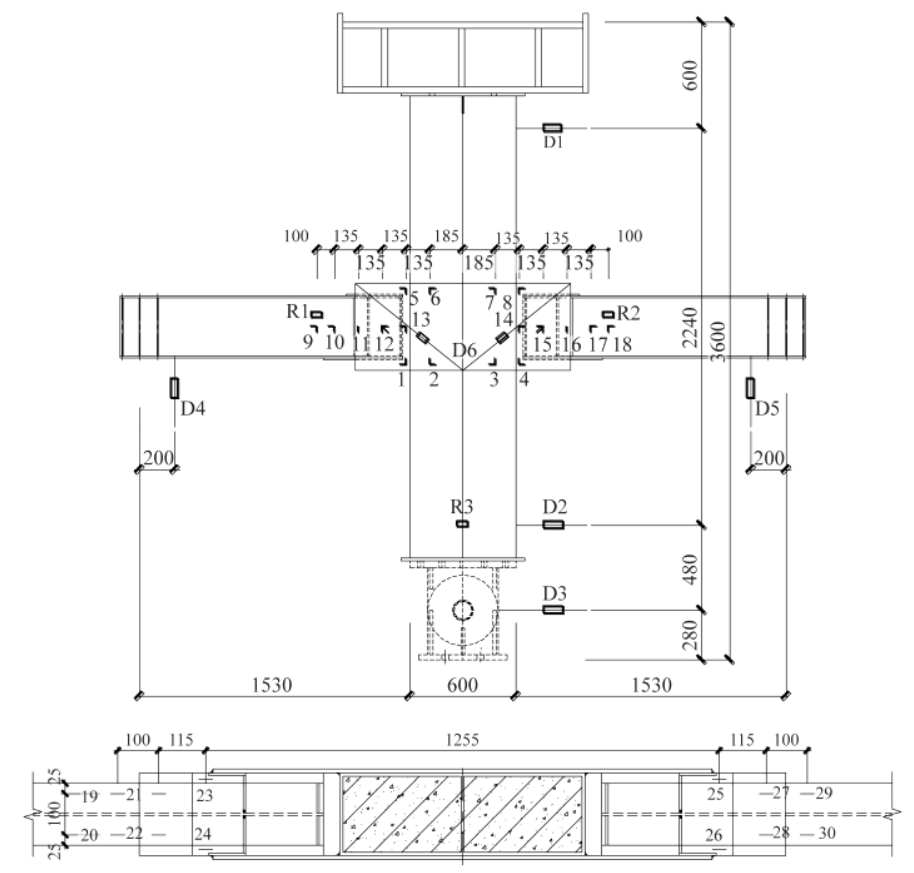

D1: magnetostrictive displacement meter; D2-D5: horizontal displacement meters;

D6: cross-displacement meter; R1-R3: inclinometers; and 1-30: strain gauges

Fig. 11 Measurement types and locations

The horizontal load applied to the specimen and the displacement of the column top were collected by the servo actuator (Fig. 11). The main control measuring point was D1, which was $2700 \mathrm{~mm}$ above the bottom section of the column. The cross-displacement meter, D6, measured the shear deformation of the specimen joints. Inclinometers R1 and R2 were placed $525 \mathrm{~mm}$ from the column wall and were used to measure the section angle of the plastic hinge area of the test piece beam. Inclinometer R3 was placed $480 \mathrm{~mm}$ from the centre of the hinge and was used to measure the section angle of the bottom section of the test column. Strain gauges, numbered 1-30, were used to measure the strain development of the beam end and side plates and evaluate the plastic development of each component.

\subsection{Comparison of load transfer mechanism}

Calculating yield strain with the information in Table 1 yielded values of 1395,1517 , and $1531 \mu \mathrm{m}$ in the beam flange, beam web, and side plate, respectively. These results were compared to the strain results collected by gauges placed at various locations during the test (Fig. 11), and with the peak load results observed in Fig. 12. 


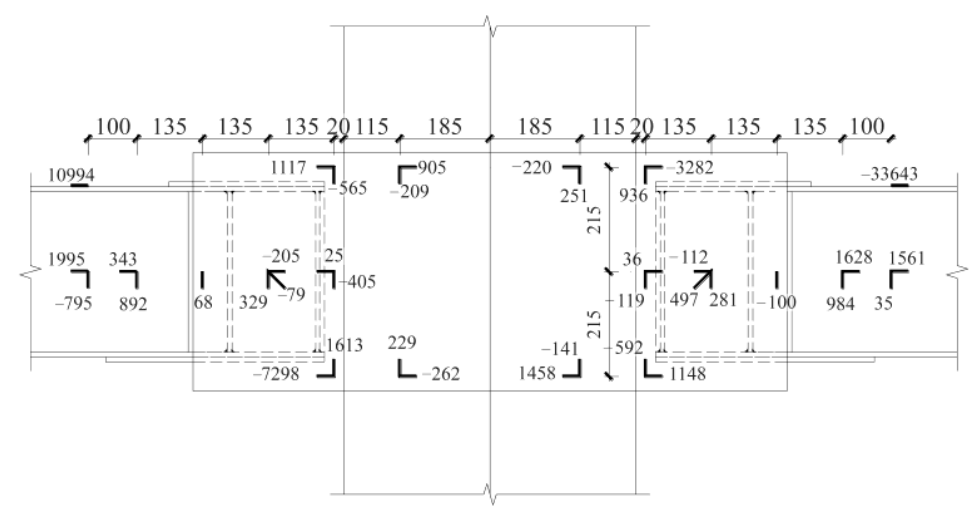

(a) Measured strains at peak loads (DSP1)

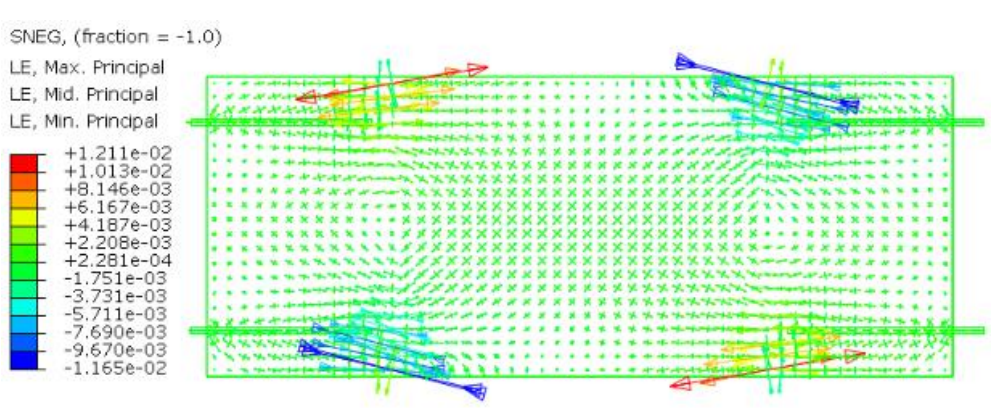

(b) Analysed strains at peak loads (DSP1)

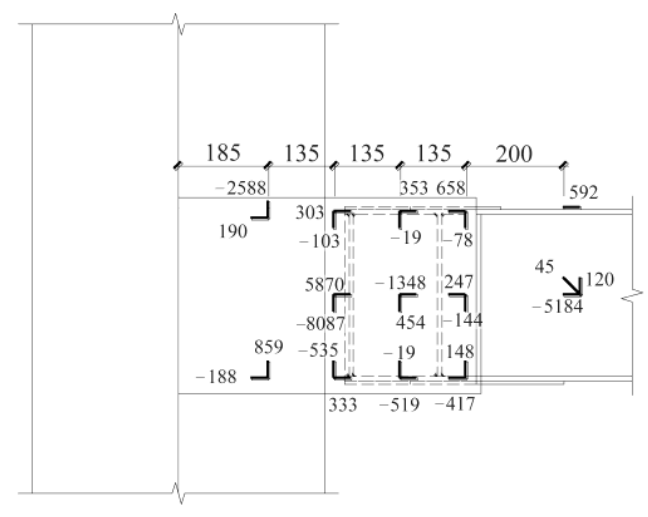

(c) Measured strains at peak loads (DSP2)
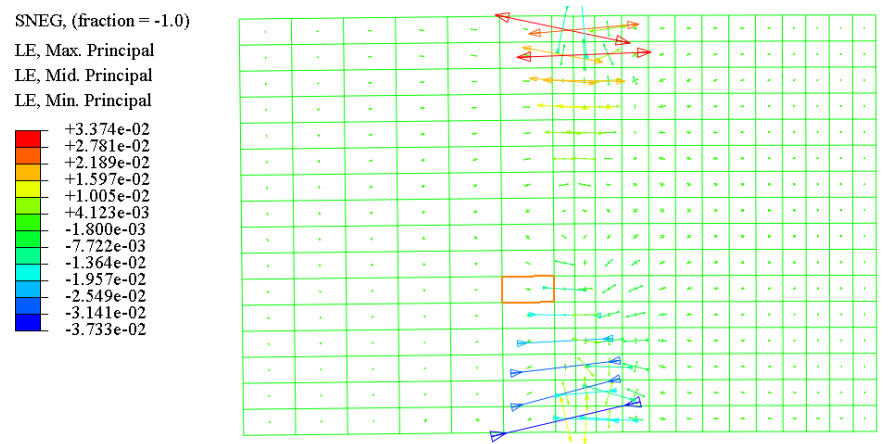

(d) Analysed strains at peak loads (DSP2)

Fig. 12 Transfer mechanism comparison

Several conclusions can be drawn from these results. First, at peak load, the beam end strain of DSP1 was 20 times higher than the yield strain. The web strain also exceeded the yield strain, and the entire section thus entered the yield state, forming a plastic hinge. Furthermore, the strains on the lower and upper sides at the beam-column gap also entered the yield state, although most areas of the side plate remained in the elastic stage. Therefore, the side plate could add strength to the joint region.

Second, most of the side plate strain for DSP2 exceeded the yield strain, while the beam flange strain was small. Additionally, the tensile strain was measured on the bottom side plate at the beam-column gap, rather than the expected compressive strain. This is because of the side plate buckling at the beam-column gap, which caused tensile strain to develop.

Third, in comparing the strain of the side plates on the two test pieces, DSP1 and DSP2, it is clear that decreasing the side plate height caused more areas on the DSP2 side plates to approach and reach the yield strain. Thus, plastic formed on the side plates at the beam-column gap. In comparing Figs. 12(a) and (b) and Figs. 12(c) and d), it is evident that the principal tensile and compressive strains on the side plate are consistent with the stress distribution, 
forming an X-shaped distribution between the left and right steel beam flanges. This indicates that these experiments supported the force transmission mechanism proposed in this study.

\subsection{Initial stiffness comparison}

Table 3

Verification results

\begin{tabular}{|c|c|c|c|}
\hline Model & $S_{\text {exp }}$ & $S_{\text {int }}$ & $\mathrm{S}_{\text {int }} / \mathrm{S}_{\exp }$ \\
\hline DPS1 & $5.56 \times 10^{10}$ & $6.11 \times 10^{10}$ & 1.09 \\
\hline DPS2 & $5.18 \times 10^{10}$ & $6.09 \times 10^{10}$ & 1.17 \\
\hline DPS1-1 & $5.64 \times 10^{10}$ & $6.12 \times 10^{10}$ & 1.08 \\
\hline DPS1-2 & $5.47 \times 10^{10}$ & $6.11 \times 10^{10}$ & 1.11 \\
\hline DPS1-3 & $5.29 \times 10^{10}$ & $6.10 \times 10^{10}$ & 1.15 \\
\hline DPS2-1 & $5.24 \times 10^{10}$ & $4.73 \times 10^{10}$ & 0.90 \\
\hline DPS2-2 & $5.40 \times 10^{10}$ & $5.51 \times 10^{10}$ & 1.02 \\
\hline DPS2-3 & $5.66 \times 10^{10}$ & $6.59 \times 10^{10}$ & 1.16 \\
\hline DPS2-4 & $5.74 \times 10^{10}$ & $6.70 \times 10^{10}$ & 1.16 \\
\hline DPS2-5 & $5.80 \times 10^{10}$ & $6.83 \times 10^{10}$ & 1.17 \\
\hline DPS2-6 & $5.86 \times 10^{10}$ & $6.91 \times 10^{10}$ & 1.17 \\
\hline \multicolumn{3}{|c|}{ Average } & 1.10 \\
\hline \multicolumn{3}{|c|}{ Standard deviation } & 0.08 \\
\hline
\end{tabular}

$\mathrm{S}_{\exp }$ is the test and finite element analysis results, $\mathrm{S}_{\text {int }}$ is the theoretical calculation results.
This analysis demonstrates that, because the theoretical formula used in this article does not consider factors such as initial defects and weld defects, it yields values greater than the experimental and numerical simulation results, although the results are relatively similar. The theoretical calculated value and ratio of the experimental and simulated values $\left(\mathrm{S}_{\text {int }} / \mathrm{S}_{\text {exp }}\right)$ has an impressive average of 1.1 and a low standard deviation of 0.08 .

In this study, the force transmission mechanism of a joint was analysed through both experimental research and numerical simulation. The component method was also introduced into the analysis of side plate joints, for the first time. The basic components of the joint force transmission were clarified, and a formula for calculating the initial rotational stiffness of the joint derived using the principle of component transmission. The following conclusions were drawn:

(1) The transmission path of the new side plate joint is as follows. The bending moment of the steel beam is simplified as the force couple acting along the flange to the side plate. After the side plate horizontal stress is transmitted to the joint, part of it is transmitted to the wall column web through the weld and part of it is directly transmitted to the lower flange of the right the side plate, and the principal strain exhibits an X-shaped distribution between the left and right steel beam flanges. The shear force in the steel beam web is transmitted to the middle of the side plate first, and then to the joint region. The side plate, steel tube web, and concrete resist the internal force in the joint region.

(2) The side plate at the beam-column gap transfers all forces at the beam end, exhibiting maximal stress and large accumulated plastic strain values. Special care should thus be taken to avoid damage in this region of the design.

(3) The formula for calculating initial rotational stiffness, established through the principle of component transmission method, is applicable to the new proposed joint. Comparing calculation results and experimental and numerical simulation results demonstrates that the formula can accurately calculate the initial rotational stiffness of the joint, thus providing a basis for engineering design and subsequent research.

The research results obtained in this study can be used to improve the design theory of the proposed joint and provide a research basis for its application to WCFT column structures.

\section{Acknowledgements}

\section{Conclusion} steel beam. The principal stress is transmitted along an S-shaped path through
According to European Code EC3 [34], the secant stiffness is taken as the initial rotational stiffness of a joint when the bending moment is $2 / 3 \times \mathrm{M}_{j, r d}$. We thus calculated the initial stiffness of each model according to (19) and compared it with the experimental and FEM results, as shown in Table 3. editing

We would like to thank Editage (www.editage.cn) for English language

\section{Funding}

This work was supported by the National Key R\&D Program of China (grant number 2017YFC0703800), and the Shaanxi Provincial Department of Construction Science and Technology Development Plan Project (grant number 2016-K86)

\section{References}

[1] Hao J.-P., Sun X.-L., Xue Q. and Fan C.-L., "Research and application of prefabricated stee structure building system", J. Eng. Mech. 34, 1, 1-13, 2017http://doi.org/10.6052/j.issn.1000-4750.2016.08.ST14.

[2] Hu B., Liu B., Wei K., et al., "Advantages of steel structure construction in the development of assembled buildings", J. Fujian Building Materials, 2, 31-33, 2020.

[3] Sun X.-L., Hao J.-P., Xue Q., Fan C.-L., Liu H.-C. and He M.-N., "Experimental study on seismic behaviour of walled concrete-filled steel tubular columns", J. Build. Struct., 39, 6 , 92-101, 2018. http://doi.org/10.14006/j.jzjgxb.2018.06.010.

[4] Hao J., Xue Q., Huang Y., et al., "Research of prefabricated building based system theory", Xi'an Univ, of Arch, \&, Tech (Natural Science Edition), 51, 1, 14-20+26, 2019. http://doi.org/10.15986/j.1006-7930.2019.01.003.

[5] Miller D.K., "Lessons from damage to steel buildings during the Northridge earthquake", Eng. Struct., 20, 4-6, 249-260, 1998. https://doi.org/10.1016/S0141-0296(97)00032-1.

[6] Houghton D.L., "Steel frame connection technology of the new millennium: satisfying heightened performance expectations with simplicity and reliability at low cost", Proc. 12th World Conference on Earthquake Engineering (12WCEE), Auckland, New Zealand, January - February 2000

[7] Sabol T.A., Engelhardt M.D., Aboutaha R.S. and Frank K.H., "Overview of the AISC Northridge moment connection test program", Proc. 11 $11^{\text {th }}$ World Conference on Earthquake Engineering, Acapulco, Mexico, June 1996.

[8] Engelhardt M.D. and Sabol T.A., "Reinforcing of steel moment connections with cover plates: benefits and limitations", Eng. Struct., 20, 4-6, 510-520, 1998 https://doi.org/10.1016/S0141-0296(97)00038-2.

[9] Houghton D.L., "The sideplate moment connection system: a design breakthrough eliminating recognized vulnerabilities in steel moment-resisting frame connections", Proc $2^{\text {nd }}$ World Conference on Steel Construction, San Sebastian, Spain, May 1998.

[10] Houghton D.L. and Karnes J.E., "Effective mitigation of progressive collapse in steel frame buildings using ductile high-capacity girder-to-column moment connection exhibiting discrete structural continuity across a failed column", Proc. Societies of American Military Engineers (SAME), National Symposium on Comprehensive Force Protection, Charleston, South Carolina, November 2001.

[11] Houghton D.L., "Prototype cyclic testing of the Side Plate ${ }^{\mathrm{TM}}$ moment connection system", Northridge Earthquake Research Conference, Los Angeles, CA, August 1997.

[12] Faridmehr I., Tahir M.M., Osman M.H. and Azimi M., "Cyclic behaviour of fully-rigid and semi-rigid steel beam-to-column connections", Int. J. Steel Struct., 21, 365-385, 2020 https://doi.org/10.1007/s13296-019-00290-8.

[13] Yakhchalian, M. "Investigation of cyclic behavior of two-sided moment connections with double-I columns and side plates", M.Sc. Thesis, Amirkabir University of Technology, Tehran, Iran, 2007 (in Persian). 
[14] Shiravand, M. "Experimental investigation of rigid beam-to-column connections in small-span bridges retrofitted against earthquake", Quarterly of Civil Engineers Association (Iran), 25, 61-69, 2007

[15] Jalali S.A., "Probabilistic seismic demand assessment of steel moment frames with side-plate connections", Scientia Iranica A, 19, 27-40, 2012.

[16] Liu H., "Seismic performance of a wall-type concrete-filled steel tubular column with a double side-plate I-beam connection", Thin-Walled Structures, 159, 1-17, 2021.

[17] Huang Y., "Mechanical behaviors of side-plate joint between walled concrete-filled steel tubular column and H-shaped steel beam", Advanced steel construction, 16, 346-353, 2020

[18] Chen S.Z. and Wang Z., "Application of modified and improved component method in the constitutive relation research for steel connections", South China University of Technology, Guangzhou, 2015.

[19] Chen Y.-Z, Tong L., Chen Y., et al, "Research developments of component method for behavior of joints in steel structures", J. Architect. and Civ. Eng., 29, 3, 81-89, 2012. https://doi.org/10.3969/j.issn.1673-2049.2012.03.013

[20] Weynand K. and Jaspart J.P., "Extension of the component method to joints in tubular construction", University of Liege, Belgium, 2001.

[21] Faella C., Piluso V. and Rizzano G., "Experimental analysis of bolted connections: snug versus preloaded bolts", J. Struct. Eng., 124, 7, 765-774, 1998 http://10.1061/(ASCE)0733-9445(1998)124:7(765).

[22] Simoes Da Silva L. and Coelho A.G., "A ductility model for steel connections", J. Constr Steel Res. 57(1), 45-70, 2001. https://doi.org/10.1016/S0143-974X(00)00009-2.

[23] Beg D., Zupancic E. and Vayas I., "On the rotation capacity of moment connections", J. Constr. Steel Res. 60(3), 601-620, 2004. https://doi.org/10.1016/S0143-974X(03)00132-9.

[24] Gill B. and Bayo E., "An alternative design for internal and external semi-rigid composite joints. Part 2: Finite element modelling and analytical study", Eng. Struct., 30, 1, 232-246, 2008. https://doi.org/10.1016/j.engstruct.2007.03.010.

[25] Lemonis M.E. and Gantes C.J., "Mechanical modeling of the nonlinear response of beam to column joints", J. Constr. Steel Res., 65, 4, 879-890, 2009. https://doi.org/10.1016/j.jcsr.2008.11.007

26] Hao J.-P., Fan C.-L., Liu H.-C., et al., "Wall-type concrete-filled steel tube concrete column steel beam double side plate connection node", ZL201821266047.2 [P] .2019-04-2.

[27] Hao J.-P., Xue Q., He M.-N., Liu H.-C., et al., "Assembled double-side plate connection node of multi-cavity concrete-filled steel tube concrete column", ZL201820370974.2 [P] 11-6, 2018.

[28] GB/T 288.1-2010, Metallic Materials: Tensile Testing at Ambient Temperature, China Standards Press, Beijing, China, 2010

[29] ABAQUS, ABAQUS Analysis User's Manual, Providence, RI, Dassault Systèmes Corp., 2012

[30] Shi Y.-J., Wang M. and Wang Y.-Q., "Experimental and constitutive model study of structural steel under cyclic loading", J. Constr. Steel Res., 67, 8, 1185-1197, 2011 https://doi.org/10.1016/j.jcsr.2011.02.011.

[31] Tao Z., Wang Z.-B. and Yu Q., "Finite element modelling of concrete-filled steel stub columns under axial compression", J. Constr. Steel Res. 89(5), 121-131, 2013 https://doi.org/10.1016/j.jcsr.2013.07.001.

[32] Wu Z., Zhang S. and Jiang S., "Calculation model of initial rotational stiffness of steel beam-to-column bolted end-plate connections", Eng. Mech. 26(6), 226-256, 2009. http://doi.org/1000-4750(2009)06-0226-07.

[33] Specification for seismic test of buildings: JGJ/T 101-2015. Beijing: China Architecture \& Building Press, 2015.

[34] EN 1993-1-8:2005, Eurocode 3: Design of Steel Structures. Part 1-8: Design of Joints, 1993. 